\title{
Feasibility and Reproducibility of Two-Dimensional Wall Motion Tracking (WMT) in Fetal Echocardiography
}

\section{(ㅇ)(우(ㅇ)}

Authors

Christian Enzensberger ${ }^{1}$, Friederike Achterberg ${ }^{1}$, Jan Degenhardt ${ }^{1}$, Aline Wolter ${ }^{1}$, Oliver Graupner ${ }^{2}$, Johannes Herrmann ${ }^{3}$,

Roland Axt-Fliedner ${ }^{1}$

\section{Affiliations}

1 Division of Prenatal Medicine, Department of OB\&GYN, University Hospital UKGM, Justus-Liebig-University, Giessen, Germany

2 Department of Obstetrics and Gynecology, Klinikum rechts der Isar, Technical University of Munich, Munich, Germany

3 Statistical Consulting Service Giessen, Statistikberatung, Giessen, Germany

Key words

fetal echocardiography, speckle tracking, cardiac function, wall motion tracking

received 12.07 .2016

revised $\quad 06.10 .2016$

accepted 13.12.2016

Bibliography

DOI http://dx.doi.org/10.1055/s-0042-124501

Ultrasound Int Open 2017; 3: E26-E33

(c) Georg Thieme Verlag KG Stuttgart · New York

ISSN 2199-7152

Correspondence

PD Dr. med. Christian Enzensberger

Division of Prenatal Medicine

Department of OB\&GYN

University Hospital UKGM

\author{
Justus-Liebig-University \\ Giessen, Klinikstrasse 33 \\ 35392 Giessen \\ Germany \\ Tel.: +49/641/98556 837, Fax: + 49/641/985 45279 \\ cenzensberger@googlemail.com
}

\section{ABSTRACT}

Objective The primary objective of this study was to determine the feasibility and reproducibility of 2-dimensional speckle tracking imaging based on the wall motion tracking (WMT) technique in fetal echocardiography. The secondary objective was to compare left and right ventricular global and segmental longitudinal peak strain values.

Methods A prospective cross-sectional study was performed. Global and segmental longitudinal peak strain values of the left ventricle (LV) and right ventricle (RV) were assessed prospectively. Based on apical 4-chamber views, cine loops were acquired and digitally stored. Strain analysis was performed offline. Intra- and interobserver variabilities were analyzed.

Results A total of 29 healthy fetuses with an echocardiogram performed between 19 and 37 weeks of gestation were included. Analysis was performed with a temporal resolution of 60 frames per second (fps). For both examiners, in all cases Cronbach's alpha was $>0.7$. The interobserver variability showed a strong agreement in $50 \%$ of the segments (ICC 0.71-0.90). The global strain values for $\mathrm{LV}$ and RV were -16.34 and $-14.65 \%$, respectively. Segmental strain analysis revealed a basis to apex gradient with the lowest strain values in basal segments and the highest strain values in apical segments.

Conclusion The assessment of fetal myocardial deformation parameters by $2 \mathrm{D}$ WMT is technically feasible with good reproducibility.

\section{Introduction}

Initially fetal echocardiography was used for the identification of structural congenital heart diseases [1,2]. Attempts to find improved methods of characterizing and risk stratifying fetuses with cardiovascular compromise, e. g., twin-twin transfusion syndrome, fetal tumors, hydrops fetalis, congenital heart disease, fetomaternal incompatibility, have turned to measures of myocardial function [3-10]. Quantification of fetal myocardial function is still challenging. To date, it has been assessed by using conventional B-mode, spectral and color Doppler interrogation or M-mode.

With the recent introduction of speckle tracking echocardiography (STE), a promising tool has been found to evaluate global and regional myocardial function in the fetus. This non-Doppler and angle-independent technique allows the quantification of myocardial dynamics and deformation in a chosen myocardial region of interest (ROI) that is based on post-processing 2D image frame-byframe analysis. Speckles, caused by the interference of energy from randomly distributed scatter echoes in the myocardium, create fine false structures, called "speckle noise". The speckles move with the tissue and can be followed over sequential frames.

Different ultrasound systems and software solutions have been used for STE mostly to establish normal values in healthy fetal $[11,12]$ and pediatric populations $[13,14]$. A few studies have been focused on special fetal conditions like twin-to-twin-transfusion syndrome [7] and intraamniotic infection [15], while other studies concentrated on cardiac anomalies [16, 17].

Although there are limitations in the application of this tool to fetuses due to fetal heart size, high heart rates and maternal and fetal movement during acquisition, several studies have been performed and report good reproducibility and feasibility [18-26]. 
However, published data in this field is very inconsistent with partially massively differing strain and strain rate data [24, 27-29]. Vendor-dependent speckle tracking imaging is usually based on grayscale B-mode images of endocardial and/or epicardial borders. Wall motion tracking (WMT) technology enables not only endoand/or epicardial border tracking but tracking of the whole myocardium. As far as we know, this technique has not been investigated yet in fetal echocardiography.

It has been shown that deformation parameters assessed by different ultrasound systems and software packages (e. g., Automated Function Imaging, GE Healthcare, Waukesha, WI [12, 19, 26, 27]; Velocity Vector Imaging (VVI), Siemens Healthcare, Erlangen, Germany [30-32]) are often not comparable [33]. Furthermore, the frame rates of the acquired video loops show a huge variation. Archived Digital Imaging and Communications in Medicine (DICOM) data with 30 frames per second (fps) was sometimes used for analysis [34, 35]. Other groups worked with the original frame rate with a frequency from $44 \mathrm{fps}$ up to more than $150 \mathrm{fps}$ [36-40].

The primary objective of this study was to determine the feasibility and reproducibility of 2D speckle tracking imaging based on the WMT technique. The secondary objective of this study was to compare left- and right-ventricular global and segmental longitudinal peak strain values.

\section{Methods}

\section{Study population}

The study population of this prospective cross-sectional study included fetuses selected from women who were referred for fetal echocardiography to the fetal heart program at the Department of Fetal Diagnosis \& Therapy, University Hospital Giessen and Marburg, from April 2014 - September 2014. The institutional review board approved this study and participants provided their written informed consent. Exclusion criteria were structural or chromosomal anomalies, twin pregnancies and conditions with a possible effect on fetal hemodynamics, e. g., evidence of fetal infection, maternal diabetes, preeclampsia, preterm labor, endocrinological disorders (e.g., thyroid disease).

All patients underwent a full morphological examination of the fetal heart in order to exclude any congenital heart defects. According to the study protocol, all patients were examined once.

\section{Echocardiography}

In every patient a complete transthoracic fetal echocardiography was performed by one experienced operator (C. E.) on a Toshiba Artida system (Toshiba Medical Systems Corporation, Otawara, Tochigi, Japan). To obtain video loops of a high resolution, zoomed B-mode of an apical 4-chamber view, a 1-5 MHz curved array probe (PVT 375 BT) was used. To achieve high frame rates, the B-mode image depth was reduced and the sector width was narrowed. For storage in raw data format, a concurrent $60 \mathrm{~Hz}$ dummy electrocardiogram (ECG) signal (phantom 320, Mueller \& Sebastiani Elektronik $\mathrm{GmbH}$, Ottobrunn, Germany) was necessary.

According to a strict protocol for every patient, at least 3 video loops of a 4-chamber view, each with a duration of $2 \mathrm{~s}$, were acquired for the left and the right ventricle. To ensure high image quality, attention was taken with respect to clear delineation of the right ventricular (RV) and left ventricular (LV) free wall as well as of the interventricular septum (IVS). The cine loops were digitally stored with the acquisition frame rate.

\section{Wall motion tracking technology}

Speckle tracking is an application of pattern matching technology to ultrasound cine data. A template image is created using a local myocardial region in the starting frame of the image data. In the next frame an algorithm searches for the local speckle pattern that most closely matches the template. A movement vector is then created using the location of the template and the matching pattern in the subsequent frame. Multiple templates are used to observe movement of the entire myocardium. The process is then repeated by creating new templates and observing their movement in the subsequent frames until the entire cardiac cycle has been assessed. This method does not make use of Doppler information, so there is no Doppler angle dependency [41].

\section{Strain analysis}

The offline analysis was performed by 2 operators on a workstation equipped with the TestDriver software (Toshiba Medical Systems Corporation, Japan). Apical 4-chamber views of good quality 2D B-mode cine loops were chosen, either displaying the right (right free wall and IVS) or the left (left free wall and IVS) ventricle. The frame rate for analysis was $60 \mathrm{fps}$ according to DICOM standard. Without the possibility of acquiring a fetal ECG, one fetal heart cycle was identified for analysis by the movement of the atrioventricular (AV) valve. End-diastole was defined by complete closure of the AV valves. The time cursor was set firstly with closure of the AV valves and secondly just before the next $A V$ valve closure. The fetal heart rate was calculated on the basis of a heart cycle duration. Based on heart rate and fps the frames per cycle (fpc) were assessed.

Strain measurements of the left and right ventricle were taken either from the same clip or from another clip if the sector width had limited the display window to 1 ventricle only. In end-diastole, endocardial markers were set along the endocardium. Beginning either just above the lateral or septal AV valve annulus, several markers were set along the endocardium in a counterclockwise direction up to the apex and back to the septal or lateral AV valve annulus. Automatically the endocardial border of a ventricle was traced (inner line) and an outer line parallel to the inner line delimitates the epicardium ( $\triangleright$ Fig. 1, left). The myocardial wall was detected with the possibility of manual adjustment of the myocardial thickness in the case of mismatching. After selection of the markers and myocardial tracing, the 2D WMT analysis of all patterns inside the user-defined region of interest (ROI) was performed through the stored fetal cardiac cycle. Accuracy of tracking was subjectively verified. Cases in which satisfactory tracking could not be obtained after several attempts were classified as inadequate and excluded from data analysis.

According to the software setup, the LV and RV myocardium were automatically divided into 6 segments, 2 basal, 2 middle and 2 apical ones, in each ventricle with 3 lateral free wall and 3 septal segments. The LV and RV each contained the lateral free wall and the IVS. 

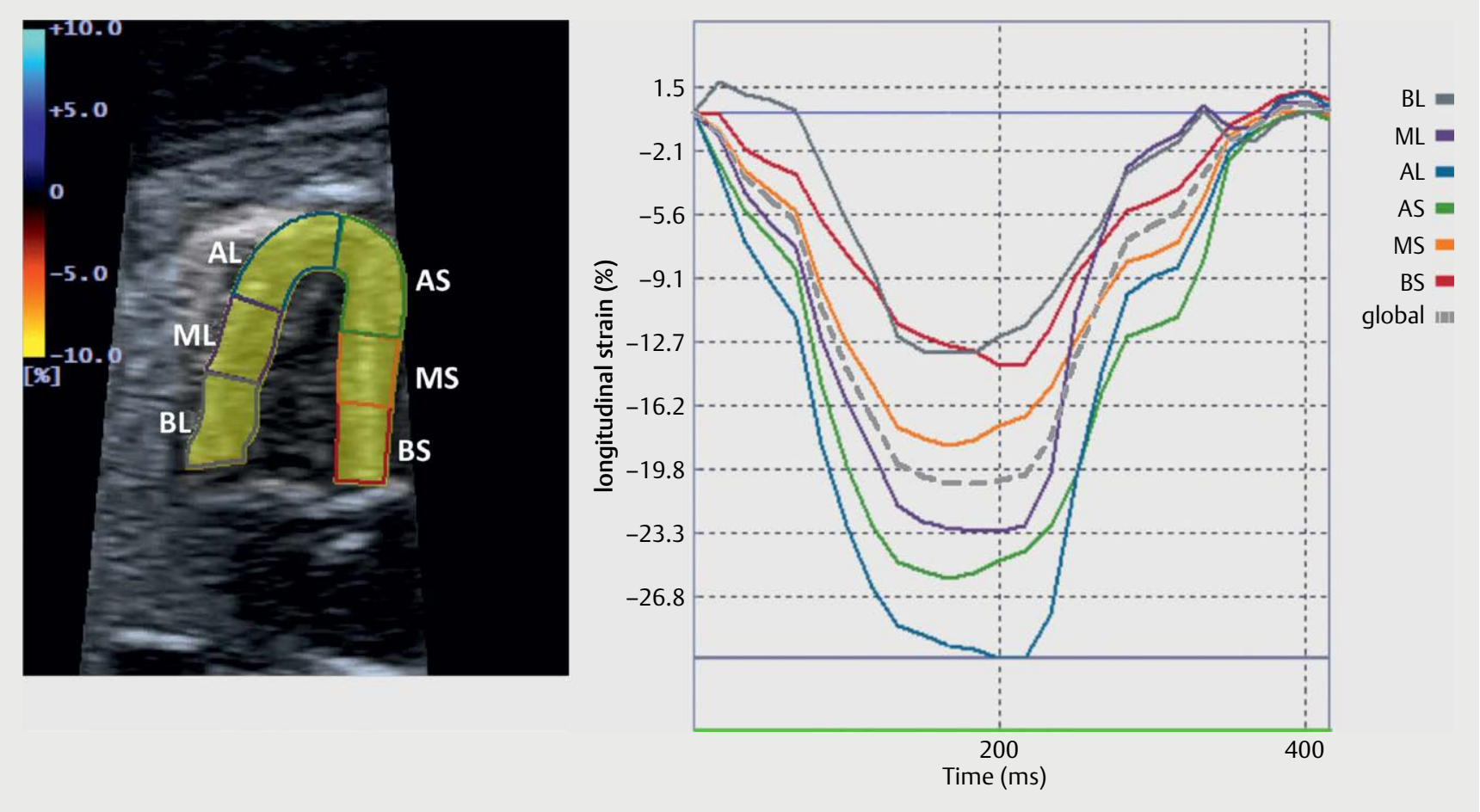

- Fig. 1 (Left) traced myocardial wall of the LV and interventricular septum with 6 segments (BL (basal lateral), ML (middle lateral), AL (apical lateral), AS (apical septal), MS (middle septal), BS (basal septal)). (Right) longitudinal strain (\%) curves of the 6 segments and global strain (\%) for one fetal heart cycle.

Based on changes in speckle location in the data set, the longitudinal strain for each segment was calculated. The Lagrangian strain, which is the difference in the end-diastolic and end-systolic length of the inner ventricular contour, is assessed with WMT technology. The results were displayed graphically as well as in numeric format for all segmental data ( $\triangleright$ Fig. 1, right).

\section{Statistical analysis}

To carry out comparisons between groups, either a general regression model or a random intercept model was used. The test was performed using the SPSS procedure MIXED (random intercept and random slopes model). Myocardial function parameters with independent data were analyzed with a general linear regression model (ANCOVA). If the analysis showed a dependency of data, the parameters were analyzed with the SPSS procedure MIXED (random intercept model). For both the linear regression model and the random intercept model, gestational age was considered as a covariate. In addition, a linear regression analysis was performed in order to investigate a possible influence of gestational age studied on mean global strain values of both ventricles.

The intraobserver and interobserver variability of the echocardiographic measurements were assessed in a subset of 10 echocardiograms from randomly selected patients at various times. 2 operators (C.E. and F.A.) analyzed the same images independently. The intraclass correlation coefficient (ICC 2-way-random, absolute agreement, single rater) was used for interobserver variability. The analysis of intraobserver variability was performed with Cronbach's alpha. Values of $0.7-0.8$ for the intraclass correlation coef- ficient or Cronbach's alpha indicate good agreement and values $>0.8$ strong agreement between measurements.

All values were considered significantly different at $\mathrm{p}<0.05$.

\section{Results}

33 fetuses were included in the study. Every patient was examined once in pregnancy. Speckle tracking analysis could be performed in 29 patients ( $88 \%$ ). 4 patients, in which speckle tracking measurements could not be successfully obtained, were excluded from data analysis. The mean gestational age was $26.5 \pm 4.9$ weeks (range 18.3-36.6 weeks), the mean fpc was 26 (range 23 - $30 \mathrm{fpc}$ ). The global strain values for LV and RV were $-16.34 \%$ and $-14.65 \%$, respectively ( $\triangleright$ Table 1 ). The difference between both ventricles was statistically significant $(p<0.001)$. The highest mean segmental strain values were found in the apical segment of the lateral free wall of the left and right ventricle, whereas the basal segments presented with the lowest values. Within the ventricular septum of both ventricles, higher mean segmental strain values were detected at the apex compared to the basal part of the ventricular septum. Segmental strain analysis revealed a basis to apex gradient with the lowest strain values in the basal and the highest strain values in the apical segments.

- Table 2 displays the results of a comparison of the basal, middle and apical strain values among each other. Significant differences were depicted within all segments of LV, RV and IVS $(p<0.05)$. Linear regression analysis revealed no significant influence of the gestational age studied on mean global strain values of both ventricles ( $p=0.44$ for $L V, p=0.44$ for $R V$ ). 
- Table 1 Mean segmental and global strain values and the $95 \%$ confidence interval for left ventricular (LV) and right ventricular (RV) free wall and the interventricular septum, analyzed either from the LV or the RV.

\begin{tabular}{|c|c|c|c|}
\hline & Segment & Strain (\%) & $95 \% \mathrm{Cl}$ \\
\hline \multirow[t]{3}{*}{ LV free wall } & Basal & -14.79 & $-15.93-(-13.66)$ \\
\hline & Middle & -16.12 & $-17.26-(-14.99)$ \\
\hline & Apical & -23.53 & $-24.67-(-22.40)$ \\
\hline \multirow[t]{3}{*}{ RV free wall } & Basal & -13.22 & $-14.49-(-11.96)$ \\
\hline & Middle & -15.10 & $-16.37-(-13.84)$ \\
\hline & Apical & -19.51 & $-20.78-(-18.25)$ \\
\hline \multirow[t]{3}{*}{ Septum LV } & Basal & -12.06 & $-13.19-(-10.93)$ \\
\hline & Middle & -14.73 & $-15.86-(-13.60)$ \\
\hline & Apical & -23.10 & $-24.23-(-21.97)$ \\
\hline \multirow[t]{3}{*}{ Septum RV } & Basal & -12.85 & $-13.79-(-11.91)$ \\
\hline & Middle & -13.97 & $-14.91-(-13.03)$ \\
\hline & Apical & -19.04 & $-19.97-(-18.10)$ \\
\hline Global strain LV & Global & -16.34 & $-16.94-(-15.75)$ \\
\hline Global strain RV & Global & -14.65 & $-15.19-(-14.12)$ \\
\hline
\end{tabular}

Within 10 fetuses of the whole study population, the intra- and interobserver variability was assessed. For both examiners, in all cases Cronbach's alpha was $>0.7$ ( $\triangleright$ Table 3 ). The interobserver variability showed a strong agreement in $50 \%$ of the segments (ICC $0.71-0.90$ in $6 / 12$ segments). There was also a strong agreement of global RV and LV peak strain values ( $\bullet$ Table 4 ).

\section{Discussion}

First, this study shows good reproducibility and feasibility of longitudinal strain analysis with high intra- and interobserver correlations in fetal echocardiography. The success rate of $88 \%$ that we achieved in our speckle tracking measurements is comparable to already published data $[20,22]$.

In recent years many different techniques, e. g., tissue Doppler imaging (TDI), have been used to investigate fetal myocardial function. By the use of TDI, it was possible to assess annular or myocardial velocities online as well as to assess strain, strain rate and cardiac time intervals offline by post-processing analysis $[9,10,42]$. One of the major criticisms of TDI has been the directional bias of the technology [43-47].

With 2D STE a relatively angle-independent technique was introduced with the possibility of determining myocardial motion (translation and rotation) and deformation indices: myocardial thickening and thinning, cardiac torsion [48-50] including apical twisting [51], radial motion and local thickening. Validation of 2D STE based on grayscale B-mode images of endocardial and epicardial borders with sonomicrometry and magnetic resonance imaging in adult and pediatric populations revealed 2D STE to be a reliable method to assess myocardial function $[18,52,53]$. Langeland et al. could assess a good agreement between ultrasound and
- Table 2 Comparison of basal, middle and apical strain values among each other for left ventricular (LV) and right ventricular (RV) free wall and the interventricular septum, analyzed either from the LV or the RV.

\begin{tabular}{|c|c|c|c|c|}
\hline & Segments & Strain (\%) & $\begin{array}{c}\Delta \text { mean } \\
\text { values }\end{array}$ & p-value \\
\hline \multirow[t]{3}{*}{ LV } & $\begin{array}{l}\text { Basal vs. } \\
\text { middle }\end{array}$ & $\begin{array}{l}-14.79 \\
\text { vs. }-16.12\end{array}$ & -1.33 & 0.023 \\
\hline & $\begin{array}{l}\text { Basal vs. } \\
\text { apical }\end{array}$ & $\begin{array}{l}-14.79 \\
\text { vs. }-23.53\end{array}$ & -8.74 & 0.000 \\
\hline & $\begin{array}{l}\text { Middle vs. } \\
\text { apical }\end{array}$ & $\begin{array}{l}-16.12 \\
\text { vs. }-23.53\end{array}$ & -7.41 & 0.000 \\
\hline \multirow[t]{3}{*}{ RV } & $\begin{array}{l}\text { Basal vs. } \\
\text { middle }\end{array}$ & $\begin{array}{l}-13.22 \\
\text { vs. }-15.10\end{array}$ & -1.88 & 0.005 \\
\hline & $\begin{array}{l}\text { Basal vs. } \\
\text { apical }\end{array}$ & $\begin{array}{l}-13.22 \\
\text { vs. }-19.51\end{array}$ & -6.29 & 0.000 \\
\hline & $\begin{array}{l}\text { Middle vs. } \\
\text { apical }\end{array}$ & $\begin{array}{l}-15.10 \\
\text { vs. }-19.51\end{array}$ & -4.41 & 0.000 \\
\hline \multirow[t]{3}{*}{ Septum LV } & $\begin{array}{l}\text { Basal vs. } \\
\text { middle }\end{array}$ & $\begin{array}{l}-12.06 \\
\text { vs. }-14.73\end{array}$ & -2.67 & 0.000 \\
\hline & $\begin{array}{l}\text { Basal vs. } \\
\text { apical }\end{array}$ & $\begin{array}{l}-12.06 \\
\text { vs. }-23.10\end{array}$ & -11.04 & 0.000 \\
\hline & $\begin{array}{l}\text { Middle vs. } \\
\text { apical }\end{array}$ & $\begin{array}{l}-14.73 \\
\text { vs. }-23.10\end{array}$ & -8.37 & 0.000 \\
\hline \multirow[t]{3}{*}{ Septum RV } & $\begin{array}{l}\text { Basal vs. } \\
\text { middle }\end{array}$ & $\begin{array}{l}-12.85 \\
\text { vs. }-13.97\end{array}$ & -1.13 & 0.047 \\
\hline & $\begin{array}{l}\text { Basal vs. } \\
\text { apical }\end{array}$ & $\begin{array}{l}-12.85 \\
\text { vs. }-19.04\end{array}$ & -6.19 & 0.000 \\
\hline & $\begin{array}{l}\text { Middle vs. } \\
\text { apical }\end{array}$ & $\begin{array}{l}-13.97 \\
\text { vs. }-19.04\end{array}$ & -5.06 & 0.000 \\
\hline
\end{tabular}

- Table 3 Analysis of intraobserver variability with Cronbach's alpha.

\begin{tabular}{|l|l|l|}
\hline Segments & Examiner 1 & Examiner 2 \\
\hline Right ventricle (RV) & & \\
\hline Basal free wall & 0.955 & 0.943 \\
\hline Middle free wall & 0.832 & 0.962 \\
\hline Apical free wall & 0.949 & 0.938 \\
\hline Basal septal & 0.924 & 0.993 \\
\hline Middle septal & 0.754 & 0.984 \\
\hline Apical septal & 0.887 & 0.944 \\
\hline Global RV & 0.956 & 0.972 \\
\hline Left ventricle (LV) & & \\
\hline Basal free wall & 0.718 & 0.879 \\
\hline Middle free wall & 0.921 & 0.974 \\
\hline Apical free wall & 0.886 & 0.968 \\
\hline Basal septal & 0.912 & 0.885 \\
\hline Middle septal & 0.957 & 0.932 \\
\hline Apical septal & 0.788 & 0.954 \\
\hline Global LV & 0.966 & 0.982 \\
\hline
\end{tabular}


- Table 4 Analysis of interobserver variability with intraclass correlation coefficient (ICC).

Segments

ICC

\section{Right ventricle (RV)}

Basal free wall 0.886

Middle free wall 0.703

Apical free wall 0.905

Basal septal 0.886

Middle septal

0.692

Apical septal

0.774

Global RV

0.892

Left ventricle (LV)

Basal free wall

0.464

Middle free wall

0.700

Apical free wall

0.479

Basal septal

0.871

Middle septal

0.946

Apical septal

0.352

Global RV sonomicrometry with an intraclass correlation coefficient of 0.80 for longitudinal components [54]. However, not only endo- and epicardial border tracking has been validated. Ishizu et al. validated LV transmural strain measured by speckle tracking imaging against sonomicrometry and reported good agreement between both techniques [55].

Our results are comparable with already published data, using different technologies, reporting good reproducibility for the application of speckle tracking imaging in the fetus. For their second trimester ultrasound-derived reference values, Kapusta et al. revealed good or excellent ICCs for intra- and interobserver variance in most cases [26]. Ta-Shma et al., who analyzed segmental and global fetal myocardial function by automatic functional imaging, achieved an interobserver and intraobserver variability that showed only a small bias among the observers with narrow $95 \%$ confidence intervals [19]. Longitudinal deformation measurement seems to be more reproducible than others, e. g., radial strain. Koopman et al. compared different speckle tracking and color Doppler techniques to measure global and regional myocardial deformation in children. For LV longitudinal strain measurements, they revealed the highest reproducibility, smallest bias, and most narrow limits of agreement for the different techniques [33].

Second, our study demonstrates a significant gradient of deformation from base to apex for longitudinal strain in both ventricles. All 3 segments (basal, middle and apical) of both lateral free wall and IVS were significantly different from each other. The apical segments of LV and RV free wall as well as of the IVS, independent of acquisition from left or right, showed significantly higher strain values. Previously published data about segmental strain differences is inconsistent. Several authors reported an apex to base gradient with significantly greater strain values either in basal segments of both ventricles [37] or in the RV only [26, 29, 38]. Other groups did not reveal significant differences between the segments [32]. Our findings are in agreement with those of Marcus et al. [56]. They established reference values for myocardial 2D strain echocardiography in a healthy pediatric and young adult cohort. Not only in their youngest patient group ( $<1$ year) but also in the other groups they revealed the highest longitudinal peak systolic strain values in the apical segments. The results are also comparable to those of Bussadori et al., who also demonstrated a base to apex gradient in their pediatric and adult population [57]. In their fetal second and third trimester population, Kim et al. also demonstrated greater strain values in the LV and the IVS [38]. Depending on different imaging techniques, variable results have been published according to left ventricular strain. In tagged MRI and 2D STE studies, higher apical than basal or middle segmental strain values have been reported, whereas tissue Doppler studies did not show a significant variation from base to apex [58-61]. This evidence was independent of the ultrasound scanner and software packages. Beside the technical impact of 2D STE using WMT technology, it might be speculated that there is a physiologic substrate in which the base-to-apex gradient is the result of the torsional mechanism of the left ventricular system and the direction of contraction of the descending fibers in the internal loop of the highly structured 3-dimensional (3D) network of myocardial cells [56]. The recent introduction of 3D STE might offer more accurate and reproducible tracking to confirm these findings. Like in 2D STE, the 3D technique was developed for strain measurement in the adult heart. Enzensberger et al. presented preliminary results of their first application of 3D WMT in fetal echocardiography. Unfortunately, due to the lack of high-frequency transducers and algorithms designed especially for fetal echocardiography, this is currently only possible in individual fetuses [62].

The 3-dimensional architecture of the myocardium and its complex motion during the cardiac cycle lead to difficulties in tracking within a 2D plane because of the speckles moving out of the 2D plane into the next frame. Consequently, only part of the real myocardial motion can be detected up to impossible tracking $[45,63]$. Therefore, different authors report the requirement of high frame rates to ensure adequate tracking. D'hooge recommends $>80$ frames per second (fps) in healthy adult hearts with a normal heart rate for an adequate assessment of motion and deformation parameters [64]. In fetal 2D STE low frame rates coupled with high heart rates have been a major problem. Many studies used frame rates of $30 \mathrm{fps}$ for deformation analysis $[20,21,24,30,65]$. It could be demonstrated that higher frame rates revealed both an increased success rate for attaining adequate tracking and analysis and an increase in absolute strain and strain rate parameters [22]. In the present study all echocardiographic images were stored automatically at a frame rate of $60 \mathrm{~Hz}$ and the tracking quality was visually acceptable. The frame rate per heart cycle (fpc) seems to be more important than the absolute frame rate. As Roesner et al. could demonstrate in simulated data, accurate strain estimates could be achieved at $>30 \mathrm{fpc}$ for longitudinal and circumferential strains [66]. Analysis of synthetic imaging data revealed that an insufficient fpc leads to systematic underestimation of strain values. Although the global peak systolic longitudinal strain acquired with $15-25 \mathrm{fpc}$ in patient, which is below our mean $\mathrm{fpc}$, data was not significantly different from a reference group acquired with 46-65 fpc [66]. 
Our global and segmental peak systolic strain values assessed by WMT technology were lower compared to other published data. One reason can be a higher frame rate used by acquisition compared to the $60 \mathrm{~Hz}$ we used in our study. Roesner et al. revealed a 2-fold higher longitudinal strain in the endocardium compared with an epicardial ROI [66]. Kim et al., who also stored their images at $60 \mathrm{~Hz}$, achieved slightly higher strain values [38]. Other authors assessed their strain analysis at $30 \mathrm{~Hz}$, showing LV strain values which are comparable to our data $[24,34,35]$. To avoid artifacts due to fetal movement or change of cardiac cycle, we used only one cardiac cycle for analysis instead of averaging over multiple cycles. This might also be a reason for the lower peak systolic strain values.

In the present study, we revealed statistically significant differences in global longitudinal peak systolic strain between LV and RV, with higher strain values in LV. This is in contrast to some previously published data. While some authors report higher strain values in the RV [25, 38], other authors did not find any difference among both ventricles $[26,28]$. The different techniques of acquisition might be responsible for this inconsistency in the published data.

For our study population regression analysis revealed stable RV and LV global peak strain values throughout pregnancy. These results are similar to already published data assessed with VVI $[21,24,30,38]$. Another recent study using the automated function imaging technique also demonstrated stable global strain values [19]. Other authors reported a statistically significant decrease in the mean global longitudinal strain of the RV, while the global strain of the LV remained constant $[25,27]$. As many studies have already shown, cardiac growth mainly occurs by myocyte enlargement rather than its proliferation in mid and late gestation $[67,68]$. Therefore, stable systolic strain values in the course of pregnancy might be explained by the fact that the number of myocytes per ventricular wall volume remains unchanged with advancing gestational age [38].

Our study was limited by the small number of patients.

To the best of our knowledge, this is the first report on the feasibility of the application of 2D STE using the WMT technology in fetal echocardiography. The aim of this study was not to establish reference values.

Originally developed for strain measurement in the adult heart, further development of STE is necessary to improve its application in fetal echocardiography and to make data more comparable between different ultrasound scanners and software packages. A first step forward was made by the cooperation of the European Association of Cardiovascular Imaging (EACVI), the American Society of Echocardiography (ASE) and a task force of interested vendors to reduce the inter-vendor variability of strain measurement by initiating standardized deformation imaging. A first consensus paper was recently published [69].

With further progress in research and technical development, STE might be a helpful tool in the clinical management of pathologies with the focus on strain analysis like intrauterine growth restriction or congenital heart diseases.

\section{Acknowledgments}

Technical support was provided by Toshiba Medical Systems Corporation, Otawara-Shi, Tochigi, Japan.
Conflict of Interest

No conflict of interest has been declared by the author(s).

\section{References}

[1] Sahn DJ, Lange LW, Allen HD et al. Quantitative real-time cross-sectional echocardiography in the developing normal human fetus and newborn. Circulation 1980; 62: 588-597

[2] Allan LD, Joseph MC, Boyd EG et al. M-mode echocardiography in the developing human fetus. Br Heart J 1982; 47: 573-583

[3] Sahn D, Kisslo ]. Report of the Council on Scientific Affairs: ultrasonic imaging of the heart: report of the Ultrasonography Task Force. Arch Intern Med 1991; 151: 1288-1294

[4] Deprest JA, Flake AW, Gratacos E et al. The making of fetal surgery. Prenat Diagn 2010; 30: 653-667

[5] Comas M, Crispi F, Cruz-Martinez R et al. Usefulness of myocardial tissue Doppler vs conventional echocardiography in the evaluation of cardiac dysfunction in early-onset intrauterine growth restriction. Am J Obstet Gynecol 2010; 203: 45.e1-e7

[6] Mäkikallio K, Räsänen J, Mäkikallio T et al. Human fetal cardiovascular profile score and neonatal outcome in intrauterine growth restriction. Ultrasound Obstet Gynecol 2008; 31: 48-54

[7] Van Mieghem T, Klaritsch P, Doné E et al. Assessment of fetal cardiac function before and after therapy for twin-to-twin transfusion syndrome. Am J Obstet Gynecol 2009; 200: 400 e1-e7

[8] Mäkikallio K, McElhinney DB, Levine JC et al. Fetal aortic valve stenosis and the evolution of hypoplastic left heart syndrome: Patient selection for fetal intervention. Circulation 2006; 113: 1401-1405

[9] Axt-Fliedner R, Graupner O, Degenhardt J et al. Evaluation of right ventricular function in the fetus with hypoplastic left heart using tissue Doppler techniques. Ultrasound Obstet Gynecol 2015; 45: 670-677

[10] Graupner O, Enzensberger C, Wieg L et al. Evaluation of right ventricular function in fetal hypoplastic left heartsyndrome by colour tissue Doppler imaging. Ultrasound Obstet Gynecol 2016; 47: 732-738

[11] Di Salvo G, Russo MG, Paladini D et al. Quantification of regional left and rightventricular longitudinal function in 75 normal fetuses using ultrasound-based strain rate and strain imaging. Ultrasound Med Biol 2005; 31: 1159-1162

[12] Di Salvo G, Russo MG, Paladini D et al. Two-dimensional strain to assess regional left and right ventricular longitudinal function in 100 normal foetuses. Eur J Echocardiogr 2008; 9: 754-756

[13] Pena JL, da Silva MG, Faria SC et al. Quantification of regional left and right ventricular deformation indices in healthy neonates by using strain rate and strain imaging. J Am Soc Echocardiogr 2009; 22: 369-375

[14] Lorch SM, Ludomirsky A, Singh GK. Maturational and growth-related changes inleft ventricular longitudinal strain and strain rate measured by two-dimensional speckle tracking echocardiography in healthy pediatric population. J Am Soc Echocardiogr 2008; 21: 1207-1215

[15] Di Naro E, Cromi A, Ghezzi F et al. Myocardialdysfunction in fetuses exposed to intraamniotic infection: new insights fromtissue Doppler and strain imaging. Am J Obstet Gynecol 2010; 203: 459.e1-e7

[16] Germanakis I, Matsui H, Gardiner HM. Myocardial strain abnormalities in fetal congenital heart disease assessed by speckle tracking echocardiography. Fetal Diagn Ther 2012; 32: 123-130

[17] Barker PCA, Houle H, Li JS et al. Global longitudinal cardiac strain and strain rate for assessment of fetal cardiac function: Novel experience with velocity vector imaging. Echocardiography 2009; 26: 28-36 
[18] Amundsen BH, Helle-Valle T, Edvardsen T et al. Noninvasive myocardial strain measurement by speckle tracking echocardiography: Validation against sonomicrometry and tagged magnetic resonance imaging. J Am Coll Cardiol 2006; 47: 789-793

[19] Ta-Shma A, Perles Z, Gavri S et al. Analysis of segmental and global function of the fetal heart using novel automatic functional imaging. J Am Soc Echocardiogr 2008; 21: 146-150

[20] Younoszai AK, Saudek DE, Emery SP et al. Evaluation of myocardial mechanics in the fetus by velocity vector imaging. J Am Soc Echocardiogr 2008; 470-474

[21] Pu DR, Zhou QC, Zhang M et al. Assessment of regional right ventricular longitudinal functions in fetus using velocity vector imaging technology. Prenat Diagn 2010; 30: 1057-1063

[22] Matsui H, Germanakis I, Kulinskaya E et al. Temporal and spatial performance of vector velocity imaging in the human fetal heart. Ultrasound Obstet Gynecol 2011; 37: 150-157

[23] Onugoren O, Gottschalk E, Dudenhausen JW et al. Assessment of long-axis ventricular function in the fetal heart with a tissue-tracking algorithm. J Perinat Med 2012; 40: 297-305

[24] Ishii T, McElhinney DB, Harrild DM et al. Circumferential and longitudinal ventricular strain in the normal human fetus. J Am Soc Echocardiogr 2012; 25: 105-111

[25] Willruth AM, Geipel AK, Berg CT et al. Comparison of global and regional right and left ventricular longitudinal peak systolic strain, strain rate and velocity in healthy fetuses using a novel feature tracking technique. J Perinat Med 2011; 39: 549-556

[26] Kapusta L, Mainzer G, Weiner Z et al. Second trimester ultrasound: Reference values for two-dimensional speckle tracking-derived longitudinal strain, strain rate and time to peak deformation of the fetal heart. J Am Soc Echocardiogr 2012; 25: 1333-1341

[27] Kapusta L, Mainzer G, Weiner $Z$ et al. Changes in fetal left and right ventricular strain mechanics during normal pregnancy. J Am Soc Echocardiogr 2013; 26: 1193-1200

[28] Barker PCA, Houle H, Li JS et al. Global longitudinal cardiac strain and strain rate for assessment of fetal cardiac function: Novel experience with velocity vector imaging. Echocardiography 2009; 26: 28-36

[29] Willruth AM, Geipel AK, Fimmers R et al. Assessment of right ventricular global and regional longitudinal peak systolic strain, strain rate and velocity in healthy fetuses and impact of gestational age using a novel speckle/feature-tracking based algorithm. Ultrasound Obstet Gynecol 2011; 37: 143-149

[30] Peng QH, Zhou QC, Zeng S et al. Evaluation of regional left ventricular longitudinal function in 151 normal fetuses using velocity vector imaging. Prenat Diagn 2009; 29: 1149-1155

[31] Van Mieghem T, Giusca S, DeKoninck P et al. Prospective assessment of fetal cardiac function with speckle tracking in healthy fetuses and recipient fetuses of twin-to-twin transfusion syndrome. J Am Soc Echocardiogr 2010; 23: 301-308

[32] Willruth AM, Geipel A, Berg C et al. Assessment of left ventricular global and regional longitudinal peak systolic strain, strain rate and velocity with feature tracking in healthy fetuses. Ultraschall Med 2012; 33: E293-E298

[33] Koopman LP, Slorach C, Hui W et al. Comparison between different speckle tracking and color tissue doppler techniques to measure global and regional myocardial deformation in children. J Am Soc Echocardiogr 2010; 23: 919-928

[34] Brooks PA, Khoo NS, Mackie AS et al. Right ventricular function in fetal hypoplastic left heart syndrome. J Am Soc Echocardiogr 2012; 25: 1068-1074

[35] Brooks PA, Khoo NS, Hornberger LK. Systolic and diastolic function of the fetal single left ventricle. J Am Soc Echocardiogr 2014; 27 : 972-977
[36] Crispi F, Sepulveda-Swatson E, Cruz-Lemini M et al. Feasibility and reproducibility of a standard protocol for 2D speckle tracking and tissue doppler-based strain and strain rate analysis of the fetal heart. Fetal Diagn Ther 2012; 32: 96-108

[37] Schubert U, Müller M, Norman M et al. Transition from fetal to neonatal life: Changes in cardiac function assessed by speckle-tracking echocardiography. Early Hum Dev 2013; 89: 803-808

[38] Kim S-H, Miyakoshi K, Kadohira I et al. Comparison of the right and left ventricular performance during the fetal development using velocity vector imaging. Early Hum Dev 2013; 89: 675-681

[39] Persico N, Fabietti I, Baffero GM et al. Fetal right ventricular contraction and relaxation times at 11-13 weeks' gestation on speckle tracking imaging. Ultrasound Obstet Gynecol 2014; 43: 284-290

[40] DeKoninck P, D'hooge J, Van Mieghem T et al. Speckle tracking echocardiography in fetuses diagnosed with congenital diaphragmatic hernia. Prenat Diagn 2014; 34: 1262-1267

[41] Kawagishi T. Speckle tracking for assessment of cardiac motion and dyssynchrony. Echocardiography 2008; 25: 1167-1171

[42] Fontana A, Zambon A, Cesana F et al. Tissue Doppler, triplane echocardiography, and speckle tracking echocardiography: different ways of measuring longitudinal myocardial velocity and deformation parameters. A comparative clinical study. Echocardiography 2012; 29: 428-437

[43] Thomas G. Tissue Doppler echocardiography - a case of right tool, wrong use. Cardiovasc Ultrasound 2004; 2: 12

[44] Marwick TH. Measurement of strain and strain rate by echocardiography: Ready for prime time? J Am Coll Cardiol 2006; 47: 1313-1327

[45] Forsey J, Friedberg MK, Mertens L. Speckle tracking echocardiography in pediatric and congenital heart disease. Echocardiography 2013; 30: 447-459

[46] Biswas M, Sudhakar S, Nanda NC et al. Two- and three-dimensional speckle tracking echocardiography: clinical applications and future directions. Echocardiography 2013; 30: 88-105

[47] Storaa C, Åberg P, Lind B et al. Effect of Angular Error on Tissue Doppler Velocities and Strain. Echocardiography 2003; 20: 581-587

[48] Kim HK, Sohn DW, Lee SE et al. Assessment of Left Ventricular Rotation and Torsion with Two-dimensional Speckle Tracking Echocardiography. J Am Soc Echocardiogr 2007; 20: 45-53

[49] Notomi Y, Lysyansky P, Setser RM et al. Measurement of ventricular torsion by two-dimensional ultrasound speckle tracking imaging. J Am Coll Cardiol 2005; 45: 2034-2041

[50] Takeuchi M, Nishikage T, Nakai H et al. The assessment of left ventricular twist in anterior wall myocardial infarction using two-dimensional speckle tracking imaging. J Am Soc Echocardiogr 2007; 20: 36-44

[51] Ashraf M, Li XK, Young MT et al. Delineation of cardiac twist by a sonographically based 2-dimensional strain analysis method: an in vitro validation study. J Ultrasound Med 2006; 25: 1193-1198

[52] Korinek J, Wang J, Sengupta PP et al. Two-dimensional strain - A Doppler-independent ultrasound method for quantitation of regional deformation: Validation in vitro and in vivo. J Am Soc Echocardiogr 2005; 18: 1247-1253

[53] Singh GK, Cupps B, Pasque M et al. Accuracy and reproducibility of strain by speckle tracking in pediatric subjects with normal heart and single ventricular physiology: A two-dimensional speckle-tracking echocardiography and magnetic resonance imaging correlative Study. J Am Soc Echocardiogr 2010; 23: 1143-1152

[54] Langeland S, D'hooge J, Wouters PF et al. Experimental validation of a new ultrasound method for the simultaneousassessment of radial and longitudinal myocardial deformation independent ofinsonation angle. Circulation 2005; 112: 2157-2162 
[55] Ishizu T, Seo Y, Enomoto Y et al. Experimental validation of left ventricular transmural strain gradient with echocardiographic two-dimensional speckle tracking imaging. Eur J Echocardiogr 2010; 11: 377-385

[56] Marcus KA, Mavinkurve-Groothuis AMC, Barends M et al. Reference values for myocardial two-dimensional strain echocardiography in a healthy pediatric and young adult cohort. J Am Soc Echocardiogr 2011; 24: 625-636

[57] Bussadori C, Moreo A, Di Donato M et al. A new 2D-based method for myocardial velocity strain and strain rate quantification in a normal adult and paediatric population: assessment of reference values. Cardiovasc Ultrasound 2009; 7: 8

[58] Marwick TH, Leano RL, Brown J et al. Myocardial strain measurement with 2-dimensional speckle-tracking echocardiography: definition of normal range. JACC Cardiovasc Imaging 2009; 2: 80-84

[59] Bogaert J, Rademakers FE. Regional nonuniformity of normal adult human left ventricle. Am J Physiol Hear Circ Physiol 2001; 280: H610-H620

[60] Leitman M, Lysiansky M, Lysyansky P et al. Circumferential and longitudinal strain in 3 myocardial layers in normal subjects and in patients with regional left ventricular dysfunction. J Am Soc Echocardiogr 2010; 23: 64-70

[61] Saito K, Okura H, Watanabe $\mathrm{N}$ et al. Comprehensive evaluation of left ventricular strain using speckle tracking echocardiography in normal adults: comparison of three-dimensional and two-dimensional approaches. J Am Soc Echocardiogr 2009; 22: 1025-1030

[62] Enzensberger C, Degenhardt J, Tenzer A et al. First Experience with three-dimensional speckle tracking (3D wall motion tracking) in fetal echocardiography. Ultraschall Med 2014; 35: 566-572
[63] De Isla LP, Balcones DV, Fernández-Golfín C et al. Three-dimensional-wall motion tracking: A new and faster tool for myocardial strain assessment: comparison with two-dimensional-wall motion Tracking. J Am Soc Echocardiogr 2009; 22: 325-330

[64] D'Hooge J, Bijnens B, Jamal F et al. High frame rate myocardial integrated backscatter. does this change our understanding of this acoustic parameter? Eur J Echocardiogr 2000; 1: 32-41

[65] Rychik J, Zeng S, Bebbington M et al. Speckle tracking-derived myocardial tissue deformation imaging in twin-twin transfusion syndrome: Differences in strain and strain rate between donor and recipient twins. Fetal Diagn Ther 2012; 32: 131-137

[66] Rösner A, Barbosa D, Aarsæther $E$ et al. The influence of frame rate on two-dimensional speckle-tracking strain measurements: a study on silico-simulated models and images recorded in patients. Eur Heart J Cardiovasc Imaging 2015; 16: 1137-1147

[67] Smolich J], Walker AM, Campbell GR et al. Left and right ventricular myocardial morphometry in fetal, neonatal, and adult sheep. Am J Physiol 1989; 257 (1 Pt 2): H1-H9

[68] Jonker SS, Zhang L, Louey S et al. Myocyte enlargement, differentiation, and proliferation kinetics in the fetal sheep heart. J Appl Physiol 2007; 102: 1130-1142

[69] Voigt JU, Pedrizzetti G, Lysyansky P et al. Definitions for a common standard for 2D speckle tracking echocardiography: consensus document of the EACVI/ASE/Industry Task Force to standardize deformation imaging. Eur Heart J Cardiovasc Imaging 2015; 16: 1-11 